\title{
Engaging Children and Young People in Digital Mental Health Interventions: Systematic Review of Modes of Delivery, Facilitators, and Barriers
}

Shaun Liverpool ${ }^{1}, \mathrm{MSc}$; Catarina Pinheiro Mota ${ }^{2,3}, \mathrm{PhD}$; Célia M D Sales ${ }^{4}, \mathrm{PhD}$; Anja Čuš ${ }^{5}$ MSc; Sara Carletto ${ }^{6}$, $\mathrm{PhD}$; Camellia Hancheva ${ }^{7}, \mathrm{PhD}$; Sónia Sousa ${ }^{8}$, PhD; Sonia Conejo Cerón ${ }^{9}$, PhD; Patricia Moreno-Peral ${ }^{9}, \mathrm{PhD}$; Giada Pietrabissa $^{10,11}$, PhD; Bettina Moltrecht ${ }^{1}$, PhD; Randi Ulberg ${ }^{12}$, PhD; Nuno Ferreira ${ }^{13}$, PhD; Julian Edbrooke-Childs ${ }^{1}$, $\mathrm{PhD}$

${ }^{1}$ Evidence-Based Practice Unit, University College London and Anna Freud National Centre for Children and Families, London, United Kingdom

${ }^{2}$ Center for Psychology, University of Porto, Porto, Portugal

${ }^{3}$ University of Trás-os-Montes and Alto Douro, Porto, Portugal

${ }^{4}$ Faculty of Psychology and Education Sciences, University of Porto, Porto, Portugal

${ }^{5}$ Department of Child and Adolescent Psychiatry, Medical University of Vienna, Vienna, Austria

${ }^{6}$ Department of Clinical and Biological Sciences, University of Turin, Turin, Italy

${ }^{7}$ Faculty of Philosophy, General, Experimental, Developmental, and Health Psychology, Sofia University, Sofia, Bulgaria

${ }^{8}$ School of Digital Technologies, Tallinn University, Tallinn, Estonia

${ }^{9}$ Biomedical Research Institute of Malaga, Málaga, Spain

${ }^{10}$ Department of Psychology, Catholic University of Milan, Milan, Italy

${ }^{11}$ Psychology Research Laboratory, IRCCS Istituto Auxologico Italiano, Milan, Italy

${ }^{12}$ Division of Mental Health and Addiction, University of Oslo, Oslo, Norway

${ }^{13}$ University of Nicosia, Nicosia, Cyprus

\section{Corresponding Author:}

Shaun Liverpool, MSc

Evidence-Based Practice Unit

University College London and Anna Freud National Centre for Children and Families

4-8 Rodney Street

London, N1 9JH

United Kingdom

Phone: 4402031089888

Email: shaun.liverpool.14@ucl.ac.uk

\begin{abstract}
Background: There is a high prevalence of children and young people (CYP) experiencing mental health (MH) problems. Owing to accessibility, affordability, and scalability, an increasing number of digital health interventions (DHIs) have been developed and incorporated into MH treatment. Studies have shown the potential of DHIs to improve MH outcomes. However, the modes of delivery used to engage CYP in digital MH interventions may differ, with implications for the extent to which findings pertain to the level of engagement with the DHI. Knowledge of the various modalities could aid in the development of interventions that are acceptable and feasible.

Objective: This review aimed to (1) identify modes of delivery used in CYP digital MH interventions, (2) explore influencing factors to usage and implementation, and (3) investigate ways in which the interventions have been evaluated and whether CYP engage in DHIs.

Methods: A literature search was performed in the Cochrane Library, Excerpta Medica dataBASE (EMBASE), Medical Literature Analysis and Retrieval System Online (MEDLINE), and PsycINFO databases using 3 key concepts "child and adolescent mental health," "digital intervention," and "engagement." Preferred Reporting Items for Systematic Reviews and Meta-Analyses guidelines were followed using rigorous inclusion criteria and screening by at least two reviewers. The selected articles were assessed for quality using the mixed methods appraisal tool, and data were extracted to address the review aims. Data aggregation and synthesis were conducted and presented as descriptive numerical summaries and a narrative synthesis, respectively.
\end{abstract}


Results: This study identified 6 modes of delivery from 83 articles and 71 interventions for engaging CYP: (1) websites, (2) games and computer-assisted programs, (3) apps, (4) robots and digital devices, (5) virtual reality, and (6) mobile text messaging. Overall, 2 themes emerged highlighting intervention-specific and person-specific barriers and facilitators to CYP's engagement. These themes encompassed factors such as suitability, usability, and acceptability of the DHIs and motivation, capability, and opportunity for the CYP using DHIs. The literature highlighted that CYP prefer DHIs with features such as videos, limited text, ability to personalize, ability to connect with others, and options to receive text message reminders. The findings of this review suggest a high average retention rate of $79 \%$ in studies involving various DHIs.

Conclusions: The development of DHIs is increasing and may be of interest to CYP, particularly in the area of MH treatment. With continuous technological advancements, it is important to know which modalities may increase engagement and help CYP who are facing $\mathrm{MH}$ problems. This review identified the existing modalities and highlighted the influencing factors from the perspective of CYP. This knowledge provides information that can be used to design and evaluate new interventions and offers important theoretical insights into how and why CYP engage in DHIs.

(J Med Internet Res 2020;22(6):e16317) doi: 10.2196/16317

\section{KEYWORDS}

mHealth; eHealth; technology; smartphone; children; adolescent mental health; mobile phone

\section{Introduction}

\section{Prevalence of Mental Health Problems in Children and Young People}

Mental health $(\mathrm{MH})$ problems in childhood and adolescence are of great importance because of their prevalence, early onset, and impact on different areas of the child's life [1]. The number of children and young people (CYP) who experience $\mathrm{MH}$ problems ranges from $10 \%$ to $20 \%$ worldwide [2]. An international study conducted in 27 countries estimated the worldwide pooled prevalence of $\mathrm{MH}$ problems to be $13.4 \%$ among CYP [3]. Specifically, anxiety and disruptive behavior disorders seem to be the most frequent presentations (Table 1) [3]. Estimates further suggest that approximately 1 in every 3 adolescents will meet the criteria for anxiety and depressive disorders [2], while 1 in 4 young people aged 16 to 24 years has experienced at least one $\mathrm{MH}$ problem in the past year [3].

Table 1. Prevalence of mental health problems in children and young people.

\begin{tabular}{ll}
\hline Mental health problem & Prevalence (\%) (adapted from Polanczyk et al [3]) \\
\hline Anxiety & 6.5 \\
Disruptive behavior & 5.7 \\
Oppositional defiance disorder & 3.6 \\
Attention-deficit hyperactivity & 3.4 \\
Depression & 2.6 \\
Conduct & 2.1 \\
\hline
\end{tabular}

\section{Benefits of Digital Health Interventions}

Addressing $\mathrm{MH}$ problems in CYP is a major public health concern [4,5], which has been impaired by low levels of youth help-seeking behavior [6]. Concerns about stigma and confidentiality, shame or embarrassment in discussing personal issues, financial costs, and/or limited access to services are among the many barriers to accessing help in this population [6-8]. In many instances, existing efficacious face-to-face interventions are adapted using digital technology as a means of addressing these barriers [9]. Digital health interventions (DHIs; eg, internet programs, apps, virtual reality environments, robotic systems) have the potential to be effective, with advantages of accessibility, anonymity, prompt feedback, cost-effectiveness, applicability in real-life contexts, and high treatment fidelity [7,10-15]. Therefore, considering the increased digital literacy and internet use among youth [16], DHIs may serve as a new way to increase accessibility to $\mathrm{MH}$ interventions in this population $[17,18]$.

\section{Efficacy of Digital Health Interventions}

The World Health Organization (WHO), the United Kingdom's National Health Service, and the US National Institute of Mental Health have identified MH apps as cost-effective and scalable solutions for addressing the MH treatment gap [19]. The efficacy of web-based therapies is well established in the treatment of several $\mathrm{MH}$ problems, including depression, anxiety, and substance misuse among adolescents [20-22]. Web-based treatment programs have also demonstrated comparable efficacy to face-to-face psychotherapy [23,24]. In addition, smartphone-based MH interventions have been shown to be a promising self-management tool for depression [25] by reducing symptoms, similar to face-to-face interventions. Equivalent results were also found for anxiety-focused mobile apps [26]. Recent systematic reviews have shown that interventions based on computerized cognitive behavioral therapy are a promising and acceptable way to reduce anxiety and depression in CYP $[17,18]$. The findings also support the clinical benefits of DHIs 
for other symptoms and disorders such as autism spectrum disorders, attention deficit, and behavioral disorders [27].

\section{Research on Digital Mental Health Interventions for Children and Young People}

Despite the growing interest in using mobile apps to deliver interventions, more research evidence is needed to support implementation in children and young people's mental health (CYPMH) services [27-29]. For instance, the evaluation of DHIs is increasingly discussed in electronic health research. A recent review showed that the majority of registered DHI evaluation trials employ common methods, such as the randomized controlled trial (RCT) study design [30]. There is much debate in the literature on appropriate methods for evaluating the impact of DHIs [31]. For instance, given the speed at which technologies advance, adaptive research designs may be more useful for increasing usability and ability to respond in a timely manner to users' experiences [32]. Considering the limitations of traditional research designs, new methodological frameworks and research designs have been developed (eg, continuous evaluation of evolving behavioral intervention technologies [33] and microrandomized trials [34]). To develop DHIs that are more useful and thereby more engaging for users, researchers agree that the impact of different functionalities on levels of engagement is important [35]. Engagement with digital behavior change interventions has been defined in the literature as a subjective experience (the user-perceived state of flow, characterized by temporal dissociation, focused attention, interest, and enjoyment) or as a behavior (extent of usage of the DHI over time or adherence) [36]. Perski et al [36] proposed an integrated conceptualization of engagement that includes both the extent (eg, amount, frequency, duration, and depth) of usage and the subjective experience of "what it feels" to be engaged (eg, attention, interest, and affect). However, engagement is usually assessed through the evaluation of the user interaction with the DHI, either by user-reported tools (eg, questionnaires, interviews, or think-aloud studies), by automated recordings of use (eg, log-ins, page views), or by recording physiological or psychophysical correlates of DHI interaction [36].

Despite the potential of DHIs, researchers have identified several limitations that influence practicality [37]. The main limitations identified were restricted tailoring to patient needs, challenges with managing comorbidity and acute crisis [38], low patient engagement and high dropout rates [39]. Although efforts have been made to reduce these occurrences with strategies such as gamification, tailoring, and guided self-help, the aforementioned difficulties remain $[27,38,39]$. In addition, further challenges arise from cautious attitudes of professionals toward DHIs, such as failure to address important aspects of the disease, data security, and accessibility [40].

\section{Rationale for This Review}

The rapid advancement of technology [41] and the increasing interest of CYP in technology [16] calls for a better understanding and evaluation of DHIs used to engage CYP with MH problems [42,43]. Engagement is commonly referred to as the active involvement of participants with the intervention, also described in previous literature as participation, adherence, noncompliance, or resistance [44]. This knowledge is crucial to support the development and evaluation of DHIs that are acceptable and feasible in CYPMH settings. This review sets out to contribute to the growing body of knowledge on digital CYPMH interventions by investigating modes of delivery used in DHIs. Although recent meta-analyses highlighted the potential effectiveness of CYPMH DHIs $[17,18,45]$, this review aimed to present information that might be of use in the development of real-world interventions that are more likely to increase engagement from CYP.

\section{Aims}

The primary aim of this study was to review the literature to identify modes of delivery used to engage CYP in digital $\mathrm{MH}$ interventions. Second, we explored barriers and facilitators for the usage and implementation of DHIs. The authors also aimed to investigate the ways in which these interventions have been evaluated and whether CYP engage in DHI research. The following questions were addressed:

1. What modes of delivery are used for engaging CYP in digital MH interventions?

2. What are the barriers and facilitators to engaging CYP in digital MH interventions?

3. How do retention rates vary in CYP digital MH intervention research?

\section{Methods}

\section{Literature Search and Search Strategy}

A literature search was conducted using the Cochrane Library, EMBASE, MEDLINE, and PsycINFO databases. All searches were carried out on the same day (December 27, 2018) to control for daily updates. Overall, 3 key concepts informed the search strategy: child and adolescent mental health, digital intervention, and engagement. Terms within similar categories were combined with $O R$ and then the results from each category were combined with $A N D$ (see Multimedia Appendix 1). The search strategy was guided by similar reviews exploring technology or engagement in child and family MH treatment [44-46], the review team discussions, and input from the University College London Institute of Child Health librarian. Reference lists of relevant articles were also scanned for additional potential studies. An initial sample of articles identified through database searching was screened first by titles and abstracts. Next, the full-text versions of potentially relevant studies were retrieved and examined in detail for eligibility at the review team meetings. Differences regarding study selection were resolved by discussion among the authors.

\section{Inclusion and Exclusion Criteria}

Screened articles were included if (1) the study targeted a CYP sample with a mean age less than 25 years; (2) the article described a DHI targeting an MH symptom (related to a primary physical/somatic condition) or the intervention was being used by CYP with MH problems; and (3) the study explored the development or testing of a DHI resulting in data on adherence, acceptability, or barriers and facilitators to engagement. Any study design was deemed acceptable for inclusion. Articles were excluded if (1) the age of the participants was not defined or if 
the mean age of the sample was 25 years and above, (2) the intervention was for the sole purpose of communicating between a health care professional and the CYP (eg, Skype, email, teleconference, or messages for appointment reminders), (3) the outcome of the study was not clearly defined or did not provide sufficient details to determine if the outcome was directly related to the intervention, and (4) the study had no human participants (eg, discussion articles describing a novel intervention).

\section{Study Selection Process}

In accordance with the Preferred Reporting Items for Systematic Reviews and Meta-Analyses guidelines [47], the flowchart presented in Figure 1 provides step-by-step details of our study selection process. After duplicates were removed, at least two members of the review team independently screened the titles and abstracts against the inclusion criteria. The full-text versions of the remaining potential articles were further examined by at least two reviewers for final inclusion. Articles excluded at this stage described interventions that were being used for communication purposes only, did not provide sufficient details of the intervention, were reviews or study protocols, were those in which the age range was not specified or was above the cutoff, targeted a non-MH condition only or targeted parents or clinicians, or had an outcome that was not related to the intervention. Any disagreements were resolved through discussions.

Figure 1. Preferred Reporting Items for Systematic Reviews and Meta-Analyses flow chart of the study selection process.

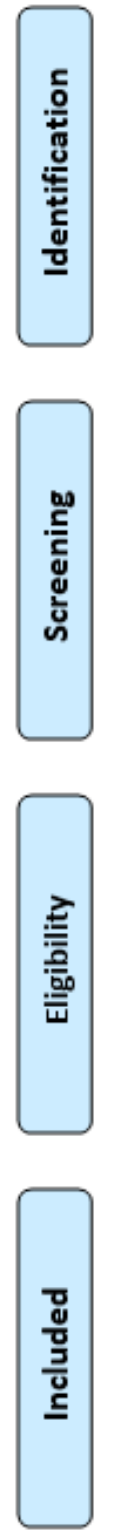

\section{Data Extraction and Quality Assessment}

A standardized form [48] that was adapted and piloted by the review team was used to extract relevant information from each article, including the following: reference, year, country, study aims, study design, sample size, setting, clinical characteristics, type of support including therapeutic treatment, retention rate, outcome, and descriptive characteristics of the sample and the intervention. Study-specific data for the second review question were also extracted at this stage to inform the thematic framework [49]. The mixed methods appraisal tool (MMAT-v2018) [50] was used to assess the methodological 
quality of each selected study. This tool was discussed in detail and selected based on its ability to report on the quality of varying study designs. Responses were rated on a categorical scale as "no," "can't tell," or "yes" to any of the methodological quality criteria. The number of items rated "yes" was counted to provide an overall score out of a possible 5 [51]. If at least one of the MMAT quality criteria was met, the methodological quality of the study was considered acceptable and the record was included. SL and a second member of the review team independently extracted all data and independently conducted the quality assessment. The 2 reviewers discussed any discrepancies and, if necessary, consulted a third team member to reach a final decision.

\section{Data Aggregation and Synthesis}

The extracted data were collated and summarized to produce a narrative summary of the study characteristics that addressed the first review question. A descriptive numerical summary was presented to group articles by the primary digital platform used to deliver the intervention. SL completed a qualitative data-driven thematic analysis [52] in addition to inductive analysis informed by the Digital Behaviour Change Framework [53] to address the second review question. Moreover, this framework and the capability, opportunity, motivation, and behavior (COM-B) model [54] were used to explore the factors influencing behavior change and intervention design. The coding process involved moving backward and forward between the data and emerging concepts. The first step generated initial codes from open coding, in which units of meanings were derived from a line-by-line analysis followed by axial coding to integrate and differentiate among subcategories. Qualitative findings relating to barriers and facilitators were coded in NVivo [55]. The review team reviewed the coding process, and any disagreements were discussed before reaching a consensus. There were no major disagreements, and consequently, the codes were developed into themes. For the purpose of addressing the third review question, the retention rate was defined as the percentage of participants completing outcome measures for at least one follow-up time point. In studies where this was not explicitly mentioned, we used the percentage of participants continuing to engage with the intervention after a specified period (ie, a time period identified by the original author).

\section{Changes to the Protocol}

Initially, the review team planned to investigate recruitment rates. However, the identified studies varied in recruitment strategies and did not provide sufficient details to address this research question. In addition, although the review team acknowledged the potential of gray literature (eg, research not published in peer-reviewed journals) to broaden the scope of systematic reviews, the team agreed to only include articles published in peer-reviewed journals. This decision was because of various reasons: (1) the popularity of technological advancements in health care; (2) the resource constraints of this study; (3) some evidence of the limited contribution of unpublished studies to the results of meta-analyses in child-relevant reviews [56]; and (4) the consideration that the aim of this systematic review was not related to efficacy and safety, which could be amenable to publication bias. No other substantial deviations from the registered protocol were made. The review protocol was registered in the International Register of Systematic Reviews (PROSPERO) [CRD42018094815].

\section{Results}

\section{Overview of the Included Articles}

The results of this systematic review are presented as a narrative synthesis [57] and, where applicable, descriptive numerical summaries are provided. A total of 83 articles published between 2001 and 2018 met the inclusion criteria (Multimedia Appendix 2) identifying 71 interventions (Multimedia Appendix 3). Of the 83 articles reviewed, almost two-third were conducted in the United States and Canada or in Australia and New Zealand. The most common type of intervention incorporated cognitive behavioral therapy as the main therapeutic modality. The mean age of the included samples was between 2 years to 24 years. Affective disorders (ie, anxiety and depression, including suicidality) were the most common presentation targets of the DHIs reviewed. Multimedia Appendix 4 provides details of the reviewed articles and Table 2 provides a summary of these findings.

A broad range of recruitment strategies were used to develop and test these DHIs, including referrals from health or school professionals; self-referrals through social media and web-based advertising; university email lists; recruitment software; or in-person advertising through posters, flyers, newspaper advertisements, word of mouth, and existing research and support groups. The following section presents the modes of delivery for DHIs, highlighting how they have been evaluated and their main features and purpose. Table 3 provides a summary of the $6 \mathrm{DHI}$ categories identified in this review, the corresponding features, and the study designs adopted. 
Table 2. Characteristics of the included articles $(\mathrm{N}=83)$.

\begin{tabular}{|c|c|}
\hline Characteristics & Values, $\mathrm{n}(\%)$ \\
\hline \multicolumn{2}{|l|}{ Country } \\
\hline United States and Canada & $31(37)$ \\
\hline Australia and New Zealand & $23(28)$ \\
\hline Europe & $21(25)$ \\
\hline Asia & $7(8)$ \\
\hline Brazil & $1(1)$ \\
\hline \multicolumn{2}{|l|}{ Therapeutic modality } \\
\hline Cognitive behavioral therapy & $39(47)$ \\
\hline Cognitive skills training mechanisms & $9(11)$ \\
\hline Social skills training or social support & $7(8)$ \\
\hline Applied behavior analysis concepts & $3(4)$ \\
\hline Single component or combinations ${ }^{\mathrm{a}}$ & $25(30)$ \\
\hline \multicolumn{2}{|l|}{ Disorders } \\
\hline Affective $^{b}$ & $38(46)$ \\
\hline Attention deficit and hyperactivity & $7(8)$ \\
\hline Autism spectrum & $12(15)$ \\
\hline Eating disorders & $4(5)$ \\
\hline Behavioral disorders $^{\mathrm{c}}$ & $10(12)$ \\
\hline Nonspecific or multiple disorders & $12(15)$ \\
\hline
\end{tabular}

${ }^{\mathrm{a} C}$ Combinations of the following strategies: therapeutic support embedded in positive psychology, behavior activation, self-regulation, learning theories, motivational interviewing, and mindfulness.

${ }^{\mathrm{b}}$ Depression, anxiety, or suicidality.

${ }^{\mathrm{c}}$ Obsessive compulsive disorder, substance abuse, selective mutism, social difficulties, and psychosis or schizophrenia.

Table 3. Summary of digital modes of delivery used in children and young people's mental health intervention.

\begin{tabular}{llc}
\hline Mode of delivery & Goals: features & Study design, n
\end{tabular}

(number of articles)

Website interven- $\quad$ - Communication: emails, text messages, social networking, web-based mes- RCT $^{\mathrm{a}}$ ( $\mathrm{n}=22$ ), pre- to posttest $(\mathrm{n}=11)$, obsertions $(n=43) \quad$ sage boards, discussion forums

- Dissemination of information: text and multimedia channels (videos, animations, and audio), games and quizzes, homework tasks, and web-based profile vational study - qualitative, quantitative, or set up with customizations

Games or computerassisted interventions $(n=23)$

Apps: web or mobile $(\mathrm{n}=10)$

Robots and digital devices $(n=3)$

Virtual reality experiences $(n=3)$

Mobile text messages $(n=1)$
- Dissemination of information: audio and movement

- Peer-to-peer communication: email reminders

- Dissemination of information, skills development, psychoeducation: photos,
stories, animations, quizzes, text messages, and multimedia (audio and videos)

- Dissemination of information, skills development, peer-to-peer communication: text message reminders, text, photos and multimedia (audio and videos) plus an opportunity to upload content

- Dissemination of information, skills development, therapeutic support: Gamification using multimedia (audio and images)

${ }^{\mathrm{a}} \mathrm{RCT}$ : randomized controlled trial.

RCT $(n=11)$, pre- to posttest $(n=8)$, observational study - quantitative or mixed methods approaches $(n=4)$

$\operatorname{RCT}(n=4)$, pre- to posttest $(n=1)$, observational study - qualitative, quantitative, or mixed methods approaches $(n=5)$

RCT ( $n=1)$, feasibility study $(n=1)$, mixed methods design $(n=1)$

Pre- to posttest $(n=2)$, posttest $(n=1)$

$\operatorname{RCT}(\mathrm{n}=1)$ 


\section{What Modes of Delivery Are Used for Engaging Children and Young People in Digital Mental Health Interventions?}

\section{Website Interventions}

Overall, 33 of the 43 articles adopted an interventional study design (22 RCTs and 11 pre- to poststudy designs). The remaining 10 studies adopted observational study designs utilizing qualitative, quantitative, or mixed methods approaches. The methodological quality of the included studies was acceptable. Qualitative studies scores ranged from 2 to 5 points, RCTs and nonrandomized quantitative studies also ranged 2 to 5 points, and mixed methods studies ranged 2 to 4 points.

The primary goal of the majority of the interventions $(n=40)$ was to transmit specific $\mathrm{MH}$ information to a targeted population. In addition, 12 of the 40 articles described interventions that were multipurpose, providing an additional opportunity for peer communication $(\mathrm{n}=7)$ or for personal health tracking $(n=4)$. YouthCHAT (see Multimedia Appendix 3 for definitions and descriptions of the interventions) provided general information in addition to providing an opportunity for personal health tracking. However, SharpTalk's primary focus was to facilitate peer-to-peer communication through discussion forums, and Manage Your Life Online functioned as a communication aid that provided an opportunity for personal health tracking.

Various features were adopted to achieve the above goals. Communication occurred digitally using emails, text messages, social networking, web-based message boards, and discussion forums. Dissemination of information occurred through text and multimedia channels (eg, videos, animations, and audio). Some interventions also utilized games and quizzes, homework tasks, and a web-based profile set up with customizations.

\section{Games or Computer-Assisted Interventions}

Overall, 20 of the 23 articles adopted an interventional study design (11 RCTs and 8 pre- to poststudy designs). The remaining 4 studies adopted observational study designs utilizing quantitative or mixed method approaches. The methodological quality of the included studies varied. RCTs scores ranged 2 to 5 points, nonrandomized quantitative studies ranged 2 to 4 points, and mixed methods ranged 3 to 5 points. No articles used qualitative methods only.

The primary goal of the majority of the interventions $(n=18)$ was to transmit specific $\mathrm{MH}$ information to a targeted population. Of the 18 interventions, 4 were multipurpose, providing additional general information to the public $(n=1)$ or an opportunity for personal health tracking $(n=4)$. In addition, 8 interventions focused on cognitive training tasks. The computer-assisted instruction intervention was used as a facilitator to assist children in developing reading skills. The social stories accessed via tablets were also used for psychoeducational purposes.

The gamification approach used to achieve the above goals was accessed either on the web or offline and incorporated photos, stories, animations, quizzes, text messages, and videos.

\section{Apps}

Of the 10 articles, 5 adopted an interventional study design (4 RCTs and 1 pre- to poststudy design). The remaining 5 articles adopted observational study designs utilizing qualitative, quantitative, or mixed methods approaches. The methodological quality of the included studies varied. Qualitative studies scored either 4 or 5 points, RCTs scores ranged 1 to 4 points, the 1 nonrandomized quantitative study scored 4 points, whereas the 2 mixed methods studies scored 3 points.

The primary goal of most apps was to transmit specific $\mathrm{MH}$ information to a targeted population. Furthermore, 3 apps were multipurpose, providing an additional opportunity for personal health tracking. The TECH app further included peer-to-peer communication.

The included apps were either web apps or mobile apps and included text message reminders, text, photos, and multimedia (videos and audio). Users also had the opportunity to upload content such as videos and photos.

\section{Robots and Digital Devices}

Of the 3 studies, 2 adopted an interventional study design, of which one (CommU) was an RCT. The study on the Fitbit Flex and Facebook adopted a mixed methods design. The study on ARIA adopted an observational study design as a pilot usability study. The methodological quality of the included studies was acceptable. The ARIA study scored 3 points, CommU scored 3 points, and the Fitbit Flex and Facebook intervention study scored 5 points.

The primary goal of ARIA and CommU was to transmit specific $\mathrm{MH}$ information to a targeted population, whereas the Fitbit Flex and Facebook intervention additionally provided an opportunity for peer communication.

ARIA and CommU utilized audio and movement to achieve the above purpose. The Fitbit Flex and Facebook synced with 2 other approaches, an app and a website, and included email reminders to achieve its purpose.

\section{Virtual Reality Experiences}

Furthermore, of the 3 studies, 2 interventions adopted pre- to posttest designs, whereas one adopted a posttest-only design (Virtual Dolphin Interaction). No RCTs were found to evaluate the identified interventions. Cave Automatic Virtual Environment also incorporated a mixed methods approach and obtained qualitative data. The methodological quality was acceptable. The Cave Automatic Virtual Environment and Collaborative Virtual Environment studies scored 3 points and the Virtual Dolphin Interaction study scored 4 points.

The primary goal of all 3 interventions was to transmit specific $\mathrm{MH}$ information to a targeted group or to facilitate skills training or provide therapeutic support. Collaborative Virtual Environment also functioned as a communication aid to facilitate collaboration within the virtual reality environment.

Cave Automatic Virtual Environment, Collaborative Virtual Environment, and Virtual Dolphin Interaction utilized features of the gamification approach to engage CYP in a more real-life experience, allowing for more immersion and movement. 


\section{Mobile Text Messages}

In addition, 1 text messaging intervention was identified and evaluated in an RCT. The methodological quality score was 3. The Educating and Supporting Inquisitive Youth in Recovery program aimed to transmit specific $\mathrm{MH}$ information to a targeted audience, to facilitate skills training or offer therapeutic support, to provide the opportunity for personal health tracking, and to signpost CYP to additional social support websites. No additional features, apart from text, were described in the study. However, participants were contacted via phone as part of the study.

\section{What Are the Barriers and Facilitators to Engaging Children and Young People in Digital Mental Health Interventions?}

Influencing factors presented as barriers and facilitators to engagement emerged as 2 broad themes encompassing 6 factors: intervention-specific influences (suitability, usability, and acceptability) and person-specific influences (motivation, capability, and opportunity). Overall, 29\% (24/83) of the included articles provided data to support these themes, 13 studies provided data for suitability, 13 for usability, and 14 provided data for acceptability. Of the 24 articles, 8 provided data to inform motivation, 4 for capability, and 13 for opportunity. A summary of concepts corresponding to the individual factors within the major themes is presented in Multimedia Appendix 5. On the basis of these findings, a conceptual framework (Figure 2) was developed, highlighting the specific components impacting engagement in CYP digital $\mathrm{MH}$ interventions, which can inform the development of, and research into, CYP DHIs.

Figure 2. A framework of factors influencing engagement in children and young people's mental health digital intervention.

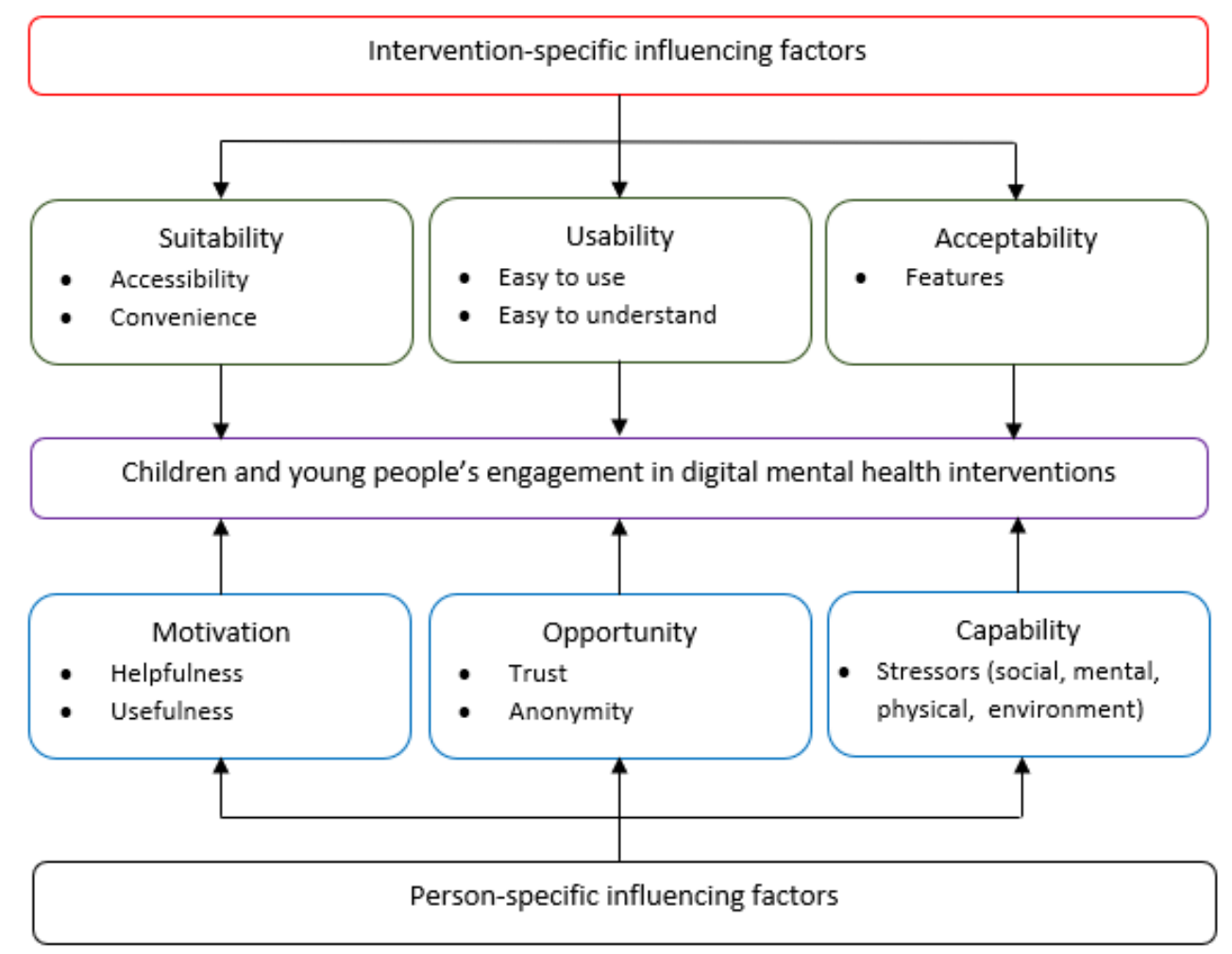

\section{Theme 1: Intervention-Specific Influences}

CYP highlighted factors related to the development of the intervention, which influenced whether they used the intervention or not. A prominent factor influencing the acceptability (ie, willingness to use) of the intervention was the features, whereby CYP highlighted certain images, specific language, and interfaces that were unappealing to them. They made suggestions and highlighted features such as videos, having less text, ability to personalize or create a profile, and ability to connect with others or receive text message reminders as encouraging their use of the intervention. CYP also suggested that providing rewards could also be a motivating factor for engaging with DHIs. Similarly, usability (ie, the degree to which the DHI was able to be used) was important for promoting engagement. Interventions that CYP favored were described as self-paced, user friendly, age appropriate, simple, and straightforward. However, in situations where CYP had problems understanding the task, or if the intervention did not provide sufficient instructions on usage, they were less inclined to continue using the DHI.

Another main factor was the suitability (ie, the degree to which the DHI is in line with daily activities) of the intervention to the lifestyle of CYP. Although CYP liked not having to travel to access the intervention and the ability to use it while at home, they were put off by technical issues or having to use media such as emails or desktop computers that they used less frequently in their daily lives. Many CYP highlighted not participating in the intervention because of a lack of time and inability to integrate the task into their everyday life. They 
suggested that flexibility concerning time and ability to bypass long waiting lists encouraged usage. In addition, they highlighted that DHIs were convenient and welcomed as they spend most of their time on the web.

\section{Theme 2: Person-Specific Influences}

Of the 6 factors, 3 were associated with person-specific barriers and facilitators to behavior change, which is in line with the COM-B model [54]. The opportunity for the intervention to be adopted was highlighted in 3 areas. First, feeling a sense of connectedness was important to CYP. They were more likely to use the intervention if it facilitated conversations with others because they wanted to know that others had similar experiences. Some CYP even indicated that they "felt alone" on the web without the support of a therapist. Trust was also of great importance to CYP, and they were reluctant to accept DHIs because of privacy concerns or uncertainties around its validity. CYP made suggestions to use trusted brand names that they were familiar with. They were also more inclined to use the interventions if there was transparency or evidence provided to support its credibility. The concerns around trust also extended to their preference for anonymity. They highlighted that anonymity made it easier to talk to a stranger on the web without feelings of embarrassment.

The second major factor identified as a person-specific influence was motivation. Some tasks were of less interest to CYP, and sometimes, they would have forgotten the existence of the intervention. However, they highlighted that curiosity and perceived need influenced their usage. Perceived usefulness of the intervention to address their needs was a major motivating factor; therefore, if the resource was viewed as unhelpful or too general, CYP were less interested in using it. However, although CYP were eager to use DHIs, the capability to engage with the intervention was sometimes affected by physical, environmental, and $\mathrm{MH}$ stressors, representing another major influencing factor.

\section{How Do Retention Rates Vary in Children and Young People Digital Mental Health Intervention Research?}

Owing to the heterogeneity in study design and intervention type, not all articles provided sufficient detail to estimate retention rates. Therefore, we were unable to include estimates for 16 of the included articles. The average retention rate across the remaining 67 articles showed almost $80 \%$ of CYP using DHIs or completing the follow-up measures. Results showed that the retention rates varied, with $11.9 \%$ (8/67) of articles achieving $100 \%$ retention and $8.95 \%(6 / 67)$ reporting less than $50 \%$ retention. Overall, $83.58 \%$ (56/67) of the included articles had a retention rate of at least $70 \%$. Subgroup analyses for approaches with a larger number of articles indicated that the average retention rate for games and computer-assisted intervention studies was $86.95 \%$, followed by websites interventions with $78.87 \%$, and apps with $78.45 \%$. Multimedia Appendix 4 shows the distribution of retention rates across studies.

\section{Discussion}

\section{Overview}

This review identified 6 modes of delivery of DHIs for CYP with $\mathrm{MH}$ issues: websites, games and computer-assisted programs, apps, robots and digital devices, virtual reality, and mobile text messaging. Overall, 2 themes emerged, highlighting intervention-specific and person-specific barriers and facilitators to engagement in DHIs. In addition, the findings of this review suggest a high average retention rate of almost $80 \%$ when the identified modalities were evaluated. Knowledge of these approaches, including influencing factors to usage from the perspective of the CYP, provided information that can be used to design and evaluate new DHIs.

\section{Explanation of the Overall Findings}

From the articles reviewed, 59 contributions were published between 2013 and 2018, with 15 records published in 2018. This is consistent with the fact that interest in applying digital technologies to $\mathrm{MH}$ practice has been increasing since the early 2000 s, and recommendations for research in this field were issued only in 2013 [58,59]. With most of the studies reviewed being conducted in developed countries, digital responses to CYPMH seem unbalanced. Previous research [60-62] highlighted the paucity of access to DHIs in low- and middle-income countries. This inequality could be because of limited resources (both financial and human), shortage of skilled personnel, infrastructure problems leading to poor internet penetration and connectivity [63], or the absence of a specific CYPMH policy [64]. However, a strong association between the severity of risk for mood disorders and social disadvantage has been documented $[65,66]$. Anxiety is the most common psychiatric condition affecting CYP in all societies [45,67-69]. It may also co-occur with other disorders, both concurrently and sequentially, leading to further health problems [68]. Therefore, it is not surprising, that $46 \%$ of articles resulting from our literature search targeted CYP with affective disorders.

The modes of delivery identified in this review are similar to those identified in other reviews exploring adolescent physical health [70,71] and $\mathrm{MH}$ [45]. The purpose of the interventions is also in line with WHO's classification of DHIs [72]. The intervention-specific and person-specific influences on CYP engagement identified in the present review mirror those of previous research on the broader technology acceptance model [73-75], the conceptual framework for engagement in Digital Behavior Change Interventions in adults [36,53], and more recently, the application of social cognitive theory to understand engagement with DHIs for trauma recovery [35]. For these models, predictors included perceived need, engagement self-efficacy, outcome expectations, and symptom severity. The proposed model of CYP engagement in digital $\mathrm{MH}$ interventions, based on the findings of the present review, builds on these models by highlighting the importance of the social context in which young people engage with DHIs. It also highlights major factors for researchers and developers in CYPMH to facilitate opportunities for a sense of connectedness. Peer-connectedness may be challenged by the necessary application of safeguarding measures. Indirect peer 
connectedness where CYP can access appropriately anonymous and asynchronous stories from real CYP with similar experiences may be one such approach, as in SharpTalk [76]. Similarly, options for anonymous usage may be particularly important for CYP's self-connectedness in terms of sharing experience in a manner that mitigates the role of stigma and shame [77,78]. Professional connectedness was particularly important in DHIs as CYP wanted to connect with a trusted support provider in lieu of connecting with a professional in real life. A key facilitator of professional connectedness was credibility in relation to evidence of the intervention's effectiveness and trust in the privacy and data security, which could be facilitated by using familiar brand names. Although characterized as an intervention-specific factor in other models [53], we characterized this as part of opportunities for connectedness and, therefore, as a person-specific factor. Future studies should explore the impact of new modes of delivery to promote a sense of connectedness in DHIs (eg, more usage of features such as ChatBots, as in the Manage Your Life Online intervention).

Other barriers and facilitators that were identified in this review also emphasize the importance of user-centered design methods when developing DHIs for CYP [53]. Through co-design workshops and focus groups with CYP, developers can ensure that a DHI's design is age appropriate, (eg, little text and using youth-engaging language) by putting a greater focus on videos and pictures, while keeping the platform user friendly. Moreover, CYP mentioned factors such as reward systems and reminders, which fall under the umbrella of persuasive design methods and have been explored in previous research [36,79]. The positive influence of these methods on user engagement and adherence to DHIs has been supported; however, quantifiable evidence from trials is still lacking [36,79]. With respect to reminders, past research has indicated a positive impact on engagement. However, excessive and undue reminders have also been shown to have opposing effects [80] Evidence from previous studies has suggested that specific behavior change techniques, such as goal setting or self-monitoring tools, relate to higher engagement [81]. This review did not extensively investigate these techniques and therefore cannot fully suggest their potential positive effects on the engagement of CYP. However, the findings of this review justify that designing DHIs with CYP in mind would be ideal to promote usage, adherence, and positive user experience and to address the barriers that some of the reviewed studies suggest.

\section{Comparison of Research Retention Rates With Other Studies}

Our findings suggest that the retention rate of CYP in digital $\mathrm{MH}$ interventions (mean retention rate of $79.2 \%$ ) was superior to that reported in face-to-face CYP MH outpatient care, where dropout affects $20 \%$ to $60 \%$ of the cases [82]. However, a direct comparison with other studies is not clear, given the diversity of criteria used for defining dropout. For instance, dropout percentages are lower when dropout is defined by the therapist's opinion than when dropout is defined by the completion of a certain number of sessions [83-85]. Our definition of retention relied on completion of the first follow-up measure or engagement for a specified period, which may explain the higher retention found. In this review, retention rates also varied widely across the studies (range $15.79 \%-100 \%$ ). A similar heterogeneity in retention rates was found in previous reviews of studies with adults receiving internet-based $\mathrm{MH}$ programs (17\%-98\%) [82], as well as in face-to-face MH interventions with CYP [83], and the adult population (varying between $17 \%-72 \%$ and $17 \%-98 \%$, respectively) [86]. Efficacy studies tend to present lower dropout rates than studies conducted in naturalistic settings [83]. Our review included a variety of empirical studies, which may have contributed to the diversity of retention rates found. Finally, the average retention rate for games and computer-assisted intervention studies was almost $10 \%$ higher than that of the other modalities, which may reflect the preference of children for interventions in game formats $[87,88]$.

\section{Digital Mental Health Care and Support of Children and Young People}

DHIs were included at various stages of the provision of psychological support. Technology-mediated programs and tools were part of prevention, assessment, treatment (psychoeducation and psychotherapy) and follow-up of $\mathrm{MH}$ care. This extensive potential of DHIs can support the WHO's initiative to identify and intervene to lessen the MH treatment gap [89]. When used as part of the initial assessment, support for shared decision making, personalized goal setting, progression, or management of transitions, DHIs are able to support CYP by enhancing their sense of agency and control. This may in turn promote greater involvement in the treatment process [90]. In several of the reviewed studies, DHIs targeting social skills training and joint attention training were used in the initial phase as a facilitator of the therapeutic process. For some specific conditions such as social anxiety, selective mutism, autism spectrum disorders, and attention-deficit conditions, the involvement of digitized programs in the preliminary phase of therapy may be an important facilitator for therapeutic success $[91,92]$. DHIs as part of the therapeutic process can be used in the periods between face-to-face treatment for interactive homework assignments, reminders, self-monitoring tools, individualized exercises, and real-time symptom assessment.

\section{Implications and Recommendations}

DHIs can be a helpful way to support and treat $\mathrm{MH}$ problems. Such tools can complement the various stages of the provision of psychological support or psychotherapy among CYP with $\mathrm{MH}$ problems. However, effective implementation and sustained usage will rely on the extent to which the design is appropriate for the intended purpose and how it will be used in practice. This understanding may help to minimize the risks associated with fear of usage that some end users experience by providing useful directions on how to design technologically responsible therapeutic approaches [93]. As a result, the findings of this review suggest that the development of DHIs should be suitable for CYP's lifestyle, focusing on ease of access, such as the ability to be used on their mobile devices at their convenience. Attention should also be given to the design of DHIs to ensure that it is not too complex and that the features are attractive to CYP. In addition, incorporating concepts that provide the CYP with a level of trust for the DHI and the ability to connect with 
others should be carefully considered. To target concerns about usefulness, developers should work with clinicians and CYP to ensure that suitable information is provided through the intervention. This collaborative approach can highlight specific ways to encourage CYP to continue engaging or increasing engagement during stressful periods.

Although this study provides insight that is valuable for the development of new interventions, future research should (1) not only focus on the effectiveness but also investigate engagement, taking into account influencing factors, as an important component of research; (2) arrive at a consensus on defining engagement and how it should be measured; (3) provide adequate reporting of recruitment and retention rates; and (4) compare CYP preferences for various modes of delivery or therapeutic approaches. Finally, this study also acknowledges the implications for practice. The findings suggest CYP interest in DHIs, and therefore, (1) efforts to improve engagement may be beneficial to CYPMH outcomes and (2) families including the CYP and clinicians should work together to identify DHIs that are suitable to the CYP's lifestyle.

\section{Strengths and Limitations}

This review adhered to established guidelines for systematic reviews [94] and adopted a comprehensive study design carried out by a team of researchers, allowing each stage of the review to be undertaken by at least two independent reviewers. Most importantly, this review highlighted the range of modes of delivery, factors influencing usage, and the variation in study types and retention of CYP in digital MH intervention studies. Our findings contribute to a broader understanding of the CYP DHI literature. However, this review is not devoid of limitations. The review team attempted to identify and include as many articles as possible; however, unknowingly and unintentionally, some papers may have been missed. This can be partly because of the challenges and inconsistencies when defining the construct of engagement resulting in a wide variety of terms used [44]. In addition, unpublished data were not included in the search strategy, which may have impacted the results of this review. Nevertheless, this approach was also seen as a further strength by ensuring that only peer-reviewed interventions were included. Moreover, the study team attempted to group interventions based on digital platforms to describe each approach. However, there may still be some variation within these groupings that make it difficult to categorize. This review was also limited as only subsamples of the total number of included articles contributed to addressing research questions 2 and 3. Therefore, caution was taken when generalizing the findings and drawing overall conclusions. In addition, because of the variability in study designs, we were prudent when averaging retention rates for this review, as follow-up measures were collected at varying time points across the selected records.

\section{Conclusions}

DHIs may be of interest to CYP, particularly in the area of MH treatment. Research on retention rates suggests high engagement of CYP in digital MH interventions that may encourage further development of DHIs in the near future. CYPMH services could benefit from this development as the included studies indicate. However, the results of this review highlighted intervention-specific and person-specific factors that influence CYP usage of digital MH interventions that should be considered. With continuous technological advancements, it is desirable to know which modalities may increase usability and adherence to better support CYP facing MH challenges.

\section{Acknowledgments}

This study was funded by the European Union's Horizon 2020 research and innovation program under the Marie Skłodowska-Curie grant agreement number 722561; TREATme, a European Network on Individualized Psychotherapy Treatment of Young People with Mental Health Disorders under the European Cooperation in Science and Technology which is supported by the EU Framework Programme Horizon 2020 action CA16102; European COMPETE2020 (POCI-01-0145-FEDER-030980); Estonian Research Council grant PUT1518; and Portuguese National funds FCT-Fundação para a Ciência e a Tecnologia, I P (PTDC/PSI-ESP/30980/2017).

\section{Authors' Contributions}

SL and JE-C conceptualized the paper. SL, CPM, CMDS, AC, S Carletto, CH, SS, S Cerón, PMP, GP, BM, and JE-C carried out selection of articles, data extraction, data analysis, and writing of the original draft. SL, CPM, CMDS, AC, S Carletto, CH, SS, S Cerón, PMP, GP, BM, RU, NF, and JE-C were involved in the writing, review, and editing.

\section{Conflicts of Interest}

JE-C is an author of one of the reviewed articles.

\section{Multimedia Appendix 1}

Search strategy.

[PDF File (Adobe PDF File), $131 \mathrm{~KB}-$ Multimedia Appendix 1]

\section{Multimedia Appendix 2}

Reviewed articles. [DOCX File , 23 KB-Multimedia Appendix 2] 


\section{Multimedia Appendix 3}

Intervention characteristics.

[PDF File (Adobe PDF File), 488 KB-Multimedia Appendix 3]

\section{Multimedia Appendix 4}

Characteristics of reviewed articles.

[PDF File (Adobe PDF File), 675 KB-Multimedia Appendix 4]

\section{Multimedia Appendix 5}

Themes and supporting codes.

[PDF File (Adobe PDF File), $361 \mathrm{~KB}-$ Multimedia Appendix 5]

\section{References}

1. Perou R, Bitsko R, Blumberg S, Pastor P, Ghandour R, Gfroerer J, Centers for Disease Control and Prevention (CDC). Mental health surveillance among children-United States, 2005-2011. MMWR Suppl 2013 May 17;62(2):1-35. [Medline: $\underline{23677130}]$

2. Kieling C, Baker-Henningham H, Belfer M, Conti G, Ertem I, Omigbodun O, et al. Child and adolescent mental health worldwide: evidence for action. Lancet 2011 Oct 22;378(9801):1515-1525. [doi: 10.1016/S0140-6736(11)60827-1] [Medline: 22008427]

3. Polanczyk GV, Salum GA, Sugaya LS, Caye A, Rohde LA. Annual research review: a meta-analysis of the worldwide prevalence of mental disorders in children and adolescents. J Child Psychol Psychiatry 2015 Mar;56(3):345-365. [doi: 10.1111/jcpp.12381] [Medline: 25649325]

4. Merikangas KR, He J, Burstein M, Swanson SA, Avenevoli S, Cui L, et al. Lifetime prevalence of mental disorders in US adolescents: results from the national comorbidity survey replication--adolescent supplement (NCS-A). J Am Acad Child Adolesc Psychiatry 2010 Oct;49(10):980-989 [FREE Full text] [doi: 10.1016/j.jaac.2010.05.017] [Medline: 20855043]

5. Lawrence D, Johnson S, Boterhoven DH, Ainley J, Zubrick S. Australian Government Department of Health. 2015. The Mental Health of Children and Adolescents: Report on the Second Australian Child and Adolescent Survey Of Mental Health and Wellbeing URL: https://www1.health.gov.au/internet/main/publishing.nsf/Content/ 9DA8CA21306FE6EDCA257E2700016945/\$File/child2.pdf [accessed 2020-05-06]

6. Gulliver A, Griffiths KM, Christensen H. Perceived barriers and facilitators to mental health help-seeking in young people: a systematic review. BMC Psychiatry 2010 Dec 30;10:113 [FREE Full text] [doi: 10.1186/1471-244X-10-113] [Medline: 21192795]

7. Donker T, Petrie K, Proudfoot J, Clarke J, Birch M, Christensen H. Smartphones for smarter delivery of mental health programs: a systematic review. J Med Internet Res 2013 Nov 15;15(11):e247 [FREE Full text] [doi: 10.2196/jmir.2791] [Medline: 24240579]

8. Clement S, Schauman O, Graham T, Maggioni F, Evans-Lacko S, Bezborodovs N, et al. What is the impact of mental health-related stigma on help-seeking? A systematic review of quantitative and qualitative studies. Psychol Med 2015 Jan;45(1):11-27. [doi: 10.1017/S0033291714000129] [Medline: 24569086]

9. Wangelin B, Szafranski D, Gros D. Telehealth technologies in evidence-based psychotherapy. In: Luiselli JK, Fischer AJ, editors. Computer-Assisted and Web-Based Innovations in Psychology, Special Education, and Health. New York, USA: Academic Press; 2016:119-140.

10. Lahiri U, Bekele E, Dohrmann E, Warren Z, Sarkar N. Design of a virtual reality based adaptive response technology for children with autism. IEEE Trans Neural Syst Rehabil Eng 2013 Jan;21(1):55-64 [FREE Full text] [doi:

10.1109/TNSRE.2012.2218618] [Medline: 23033333]

11. Diehl JJ, Schmitt LM, Villano M, Crowell CR. The clinical use of robots for individuals with autism spectrum disorders: a critical review. Res Autism Spectr Disord 2012 Jan;6(1):249-262 [FREE Full text] [doi: 10.1016/j.rasd.2011.05.006] [Medline: 22125579]

12. van Voorhees BW, Mahoney N, Mazo R, Barrera AZ, Siemer CP, Gladstone TR, et al. Internet-based depression prevention over the life course: a call for behavioral vaccines. Psychiatr Clin North Am 2011 Mar;34(1):167-183 [FREE Full text] [doi: 10.1016/j.psc.2010.11.002] [Medline: 21333846]

13. Yuan SN, Ip HH. Using virtual reality to train emotional and social skills in children with autism spectrum disorder. London J Prim Care (Abingdon) 2018;10(4):110-112 [FREE Full text] [doi: 10.1080/17571472.2018.1483000] [Medline: 30083244]

14. Alvarez-Jimenez M, Alcazar-Corcoles M, González-Blanch C, Bendall S, McGorry P, Gleeson J. Online, social media and mobile technologies for psychosis treatment: a systematic review on novel user-led interventions. Schizophr Res 2014 Jun;156(1):96-106. [doi: 10.1016/j.schres.2014.03.021] [Medline: 24746468]

15. Olff M. Mobile mental health: a challenging research agenda. Eur J Psychotraumatol 2015;6:27882 [FREE Full text] [doi: 10.3402/ejpt.v6.27882] [Medline: 25994025] 
16. OfCom. 2018. Children and Parents: Media Use and Attitudes Report URL: https://www.ofcom.org.uk/_data/assets/ pdf file/0024/134907/Children-and-Parents-Media-Use-and-Attitudes-2018.pdf [accessed 2020-05-06]

17. Pennant ME, Loucas CE, Whittington C, Creswell C, Fonagy P, Fuggle P, Expert Advisory Group. Computerised therapies for anxiety and depression in children and young people: a systematic review and meta-analysis. Behav Res Ther 2015 Apr;67:1-18. [doi: 10.1016/j.brat.2015.01.009] [Medline: 25727678]

18. Richardson T, Stallard P, Velleman S. Computerised cognitive behavioural therapy for the prevention and treatment of depression and anxiety in children and adolescents: a systematic review. Clin Child Fam Psychol Rev 2010 Sep;13(3):275-290. [doi: 10.1007/s10567-010-0069-9] [Medline: 20532980]

19. Chandrashekar P. Do mental health mobile apps work: evidence and recommendations for designing high-efficacy mental health mobile apps. Mhealth 2018;4:6 [FREE Full text] [doi: 10.21037/mhealth.2018.03.02] [Medline: 29682510]

20. Donovan CL, March S. Computer-based treatment programs for youth anxiety: a systematic review. Psychopathology Rev 2014 Jul 28;a1(1):130-156. [doi: 10.5127/pr.033613]

21. Ebert DD, Zarski A, Christensen H, Stikkelbroek Y, Cuijpers P, Berking M, et al. Internet and computer-based cognitive behavioral therapy for anxiety and depression in youth: a meta-analysis of randomized controlled outcome trials. PLoS One 2015;10(3):e0119895 [FREE Full text] [doi: 10.1371/journal.pone.0119895] [Medline: 25786025]

22. Reyes-Portillo JA, Mufson L, Greenhill LL, Gould MS, Fisher PW, Tarlow N, et al. Web-based interventions for youth internalizing problems: a systematic review. J Am Acad Child Adolesc Psychiatry 2014 Dec;53(12):1254-70.e5. [doi: 10.1016/j.jaac.2014.09.005] [Medline: 25457924]

23. Christensen H, Batterham P, Calear A. Online interventions for anxiety disorders. Curr Opin Psychiatry 2014 Jan;27(1):7-13. [doi: 10.1097/YCO.0000000000000019] [Medline: 24257123]

24. Sethi S. Treating youth depression and anxiety: a randomised controlled trial examining the efficacy of computerised versus face-to-face cognitive behaviour therapy. Aust Psychol 2013 Feb 14;48(4):249-257. [doi: 10.1111/ap.12006]

25. Firth J, Torous J, Nicholas J, Carney R, Pratap A, Rosenbaum S, et al. The efficacy of smartphone-based mental health interventions for depressive symptoms: a meta-analysis of randomized controlled trials. World Psychiatry 2017 Oct;16(3):287-298 [FREE Full text] [doi: 10.1002/wps.20472] [Medline: 28941113]

26. Ly KH, Topooco N, Cederlund H, Wallin A, Bergström J, Molander O, et al. Smartphone-supported versus full behavioural activation for depression: a randomised controlled trial. PLoS One 2015;10(5):e0126559 [FREE Full text] [doi: 10.1371/journal.pone.0126559] [Medline: 26010890]

27. Wozney L, McGrath PJ, Gehring ND, Bennett K, Huguet A, Hartling L, et al. eMental healthcare technologies for anxiety and depression in childhood and adolescence: systematic review of studies reporting implementation outcomes. JMIR Ment Health 2018 Jun 26;5(2):e48 [FREE Full text] [doi: 10.2196/mental.9655] [Medline: 29945858]

28. Grist R, Porter J, Stallard P. Mental health mobile apps for preadolescents and adolescents: a systematic review. J Med Internet Res 2017 May 25;19(5):e176 [FREE Full text] [doi: 10.2196/jmir.7332] [Medline: 28546138]

29. Scholten H, Granic I. Use of the principles of design thinking to address limitations of digital mental health interventions for youth: viewpoint. J Med Internet Res 2019 Jan 14;21(1):e11528 [FREE Full text] [doi: 10.2196/11528] [Medline: $\underline{31344671]}$

30. Pham Q, Wiljer D, Cafazzo JA. Beyond the randomized controlled trial: a review of alternatives in mhealth clinical trial methods. JMIR Mhealth Uhealth 2016 Sep 9;4(3):e107 [FREE Full text] [doi: 10.2196/mhealth.5720] [Medline: 27613084]

31. Michie S, Yardley L, West R, Patrick K, Greaves F. Developing and evaluating digital interventions to promote behavior change in health and health care: recommendations resulting from an international workshop. J Med Internet Res 2017 Jun 29;19(6):e232 [FREE Full text] [doi: 10.2196/jmir.7126] [Medline: 28663162]

32. Mohr DC, Schueller SM, Riley WT, Brown CH, Cuijpers P, Duan N, et al. Trials of intervention principles: evaluation methods for evolving behavioral intervention technologies. J Med Internet Res 2015 Jul 8;17(7):e166 [FREE Full text] [doi: 10.2196/jmir.4391] [Medline: 26155878]

33. Mohr DC, Cheung K, Schueller SM, Hendricks Brown C, Duan N. Continuous evaluation of evolving behavioral intervention technologies. Am J Prev Med 2013 Oct;45(4):517-523 [FREE Full text] [doi: 10.1016/j.amepre.2013.06.006] [Medline: 24050429]

34. Klasnja P, Hekler EB, Shiffman S, Boruvka A, Almirall D, Tewari A, et al. Microrandomized trials: an experimental design for developing just-in-time adaptive interventions. Health Psychol 2015 Dec;34S:1220-1228 [FREE Full text] [doi: 10.1037/hea0000305] [Medline: 26651463]

35. Yeager CM, Benight CC. If we build it, will they come? Issues of engagement with digital health interventions for trauma recovery. Mhealth 2018;4:37 [FREE Full text] [doi: 10.21037/mhealth.2018.08.04] [Medline: 30363749]

36. Perski O, Blandford A, West R, Michie S. Conceptualising engagement with digital behaviour change interventions: a systematic review using principles from critical interpretive synthesis. Transl Behav Med 2017 Jun;7(2):254-267 [FREE Full text] [doi: 10.1007/s13142-016-0453-1] [Medline: 27966189]

37. Vis C, Kleiboer A, Prior R, Bønes E, Cavallo M, Clark SA, et al. Implementing and up-scaling evidence-based emental health in Europe: the study protocol for the MasterMind project. Internet Interv 2015 Nov;2(4):399-409. [doi:

10.1016/j.invent.2015.10.002] 
38. Andersson G, Titov N. Advantages and limitations of internet-based interventions for common mental disorders. World Psychiatry 2014 Feb;13(1):4-11 [FREE Full text] [doi: 10.1002/wps.20083] [Medline: 24497236]

39. Musiat P, Tarrier N. Collateral outcomes in e-mental health: a systematic review of the evidence for added benefits of computerized cognitive behavior therapy interventions for mental health. Psychol Med 2014 Nov;44(15):3137-3150. [doi: 10.1017/S0033291714000245] [Medline: 25065947]

40. Schuster R, Pokorny R, Berger T, Topooco N, Laireiter A. The advantages and disadvantages of online and blended therapy: survey study amongst licensed psychotherapists in Austria. J Med Internet Res 2018 Dec 18;20(12):e11007 [FREE Full text] [doi: 10.2196/11007] [Medline: $\underline{\text { 30563817] }}$

41. Ericsson - A World of Communication. 2015. Ericsson Mobility Report: 70 percent of world's population using smartphones by 2020 URL: https:/?/www.?ericsson.com/?en/?press-releases/?2015/?6/

?ericsson-mobility-report-70-percent-of-worlds-population-using-smartphones-by-2020 [accessed 2020-02-12]

42. Becker KD, Lee BR, Daleiden EL, Lindsey M, Brandt NE, Chorpita BF. The common elements of engagement in children's mental health services: which elements for which outcomes? J Clin Child Adolesc Psychol 2015;44(1):30-43. [doi: 10.1080/15374416.2013.814543] [Medline: 23879436]

43. Gopalan G, Goldstein L, Klingenstein K, Sicher C, Blake C, McKay MM. Engaging families into child mental health treatment: updates and special considerations. J Can Acad Child Adolesc Psychiatry 2010 Aug;19(3):182-196 [FREE Full text] [Medline: 20842273]

44. Haine-Schlagel R, Walsh NE. A review of parent participation engagement in child and family mental health treatment. Clin Child Fam Psychol Rev 2015 Jun;18(2):133-150 [FREE Full text] [doi: 10.1007/s10567-015-0182-x] [Medline: 25726421]

45. Hollis C, Falconer CJ, Martin JL, Whittington C, Stockton S, Glazebrook C, et al. Annual research review: digital health interventions for children and young people with mental health problems - a systematic and meta-review. J Child Psychol Psychiatry 2017 Apr;58(4):474-503. [doi: 10.1111/jcpp.12663] [Medline: 27943285]

46. Kim H, Munson MR, McKay MM. Engagement in mental health treatment among adolescents and young adults: a systematic review. Child Adolesc Soc Work J 2012 Mar 3;29(3):241-266. [doi: 10.1007/s10560-012-0256-2]

47. Moher D, Liberati A, Tetzlaff J, Altman DG, PRISMA Group. Preferred reporting items for systematic reviews and meta-analyses: the PRISMA statement. Ann Intern Med 2009 Aug 18;151(4):264-9, W64. [doi: 10.7326/0003-4819-151-4-200908180-00135] [Medline: 19622511]

48. Munn Z, Aromataris E, Tufanaru C, Stern C, Porritt K, Farrow J, et al. The development of software to support multiple systematic review types: the joanna briggs institute system for the unified management, assessment and review of information (JBI SUMARI). Int J Evid Based Healthc 2019 Mar;17(1):36-43. [doi: 10.1097/XEB.0000000000000152] [Medline: 30239357]

49. Gale NK, Heath G, Cameron E, Rashid S, Redwood S. Using the framework method for the analysis of qualitative data in multi-disciplinary health research. BMC Med Res Methodol 2013 Sep 18;13:117 [FREE Full text] [doi:

10.1186/1471-2288-13-117] [Medline: 24047204]

50. Hong QN, Fàbregues S, Bartlett G, Boardman F, Cargo M, Dagenais P, et al. The mixed methods appraisal tool (MMAT) version 2018 for information professionals and researchers. Educ Inform J 2018 Dec 18;34(4):285-291. [doi: 10.3233/efi-180221]

51. Pluye P, Gagnon M, Griffiths F, Johnson-Lafleur J. A scoring system for appraising mixed methods research, and concomitantly appraising qualitative, quantitative and mixed methods primary studies in mixed studies reviews. Int J Nurs Stud 2009 Apr;46(4):529-546. [doi: 10.1016/j.ijnurstu.2009.01.009] [Medline: 19233357]

52. Braun V, Clarke V. Using thematic analysis in psychology. Qual Res Psychol 2006 Jan;3(2):77-101. [doi: 10.1191/1478088706qp063oa]

53. Kayser L, Nøhr C, Bertelsen P, Botin L, Villumsen S, Showell C, et al. Theory and practice in digital behaviour change: a matrix framework for the co-production of digital services that engage, empower and emancipate marginalised people living with complex and chronic conditions. Informatics 2018 Nov 9;5(4):41. [doi: 10.3390/informatics5040041]

54. Michie S, Atkins L, West R. The Behaviour Change Wheel: A Guide to Designing Interventions. Sutton, UK: Silverback Publishing; 2014.

55. Jackson K, Bazeley P. Qualitative Data Analysis with NVivo. Third Edition. Thousand Oaks, CA: Sage Publications; 2019.

56. Hartling L, Featherstone R, Nuspl M, Shave K, Dryden DM, Vandermeer B. Grey literature in systematic reviews: a cross-sectional study of the contribution of non-English reports, unpublished studies and dissertations to the results of meta-analyses in child-relevant reviews. BMC Med Res Methodol 2017 Apr 19;17(1):64 [FREE Full text] [doi: 10.1186/s12874-017-0347-z] [Medline: 28420349]

57. Popay J, Roberts H, Sowden A, Petticrew M, Arai L, Rodgers M, et al. CiteSeerX. 2006. Guidance on the Conduct of Narrative Synthesis in Systematic Reviews: A Product from the ESRC Methods Programme URL: http://citeseerx.ist.psu.edu/ viewdoc/download?doi=10.1.1.178.3100\&rep=rep1\&type=pdf [accessed 2020-05-14]

58. Hatch A, Hoffman JE, Ross R, Docherty JP. Expert consensus survey on digital health tools for patients with serious mental illness: optimizing for user characteristics and user support. JMIR Ment Health 2018 Jun 12;5(2):e46 [FREE Full text] [doi: 10.2196/mental.9777] [Medline: 29895514] 
59. Mohr DC, Burns MN, Schueller SM, Clarke G, Klinkman M. Behavioral intervention technologies: evidence review and recommendations for future research in mental health. Gen Hosp Psychiatry 2013;35(4):332-338 [FREE Full text] [doi: 10.1016/j.genhosppsych.2013.03.008] [Medline: 23664503]

60. Sobowale K, Nguyen M, Weiss B, Van TT, Trung LT. Acceptability of internet interventions for youth mental health in Vietnam. Glob Ment Health (Camb) 2016;3:e22 [FREE Full text] [doi: 10.1017/gmh.2016.18] [Medline: 28596890]

61. Cummings JR, Gaydos LM, Mensa-Kwao A, Song M, Blake SC. Perspectives on caregiver-focused mhealth technologies to improve mental health treatment for low-income youth with ADHD. J Technol Behav Sci 2019 Mar;4(1):6-16 [FREE Full text] [doi: 10.1007/s41347-018-0066-2] [Medline: 31106258 ]

62. Eustache E, Gerbasi ME, Fawzi MC, Fils-Aimé JR, Severe J, Raviola GJ, et al. High burden of mental illness and low utilization of care among school-going youth in Central Haiti: a window into the youth mental health treatment gap in a low-income country. Int J Soc Psychiatry 2017 May;63(3):261-274 [FREE Full text] [doi: 10.1177/0020764017700174] [Medline: 28367719]

63. Chakrabarti S, Shah R. Telepsychiatry in the developing world: whither promised joy? Indian J Soc Psychiatry 2016;32(3):273. [doi: 10.4103/0971-9962.193200]

64. Shatkin JP, Belfer ML. The global absence of child and adolescent mental health policy. Child Adolesc Ment Health 2004 Sep;9(3):104-108. [doi: 10.1111/j.1475-3588.2004.00090.x]

65. McLaughlin KA, Costello EJ, Leblanc W, Sampson NA, Kessler RC. Socioeconomic status and adolescent mental disorders. Am J Public Health 2012 Sep;102(9):1742-1750 [FREE Full text] [doi: 10.2105/AJPH.2011.300477] [Medline: 22873479]

66. Hartwell H. Social inequality and mental health. J R Soc Promot Health 2008 May;128(3):98. [doi: 10.1177/14664240081280030701] [Medline: 18595622]

67. Patel V, Flisher AJ, Hetrick S, McGorry P. Mental health of young people: a global public-health challenge. Lancet 2007 Apr 14;369(9569):1302-1313. [doi: 10.1016/S0140-6736(07)60368-7] [Medline: 17434406]

68. Langhaug LF, Pascoe SJ, Mavhu W, Woelk G, Sherr L, Hayes RJ, et al. High prevalence of affective disorders among adolescents living in rural Zimbabwe. J Community Health 2010 Aug;35(4):355-364 [FREE Full text] [doi: 10.1007/s10900-010-9261-6] [Medline: 20571897]

69. Merikangas KR, Nakamura EF, Kessler RC. Epidemiology of mental disorders in children and adolescents. Dialogues Clin Neurosci 2009;11(1):7-20 [FREE Full text] [Medline: 19432384]

70. Devine KA, Viola AS, Coups EJ, Wu YP. Digital health interventions for adolescent and young adult cancer survivors. JCO Clin Cancer Inform 2018 Dec;2:1-15 [FREE Full text] [doi: 10.1200/CCI.17.00138] [Medline: 30652583]

71. Rose T, Barker M, Jacob CM, Morrison L, Lawrence W, Strömmer S, et al. A systematic review of digital interventions for improving the diet and physical activity behaviors of adolescents. J Adolesc Health 2017 Dec;61(6):669-677 [FREE Full text] [doi: 10.1016/j.jadohealth.2017.05.024] [Medline: 28822682]

72. World Health Organization. 2018. Classification of Digital Health Interventions V1.0: A Shared Language to Describe the Uses of Digital Technology for Health URL: https://www.who.int/reproductivehealth/publications/mhealth/ classification-digital-health-interventions/en/ [accessed 2020-05-14]

73. Venkatesh V, Morris MG, Davis GD, Davis FD. User acceptance of information technology: toward a unified view. MIS Q 2003;27(3):425. [doi: 10.2307/30036540]

74. Davis FD. Perceived usefulness, perceived ease of use, and user acceptance of information technology. MIS Q 1989 Sep;13(3):319. [doi: 10.2307/249008]

75. Rahimi B, Nadri H, Afshar HL, Timpka T. A systematic review of the technology acceptance model in health informatics. Appl Clin Inform 2018 Jul;9(3):604-634 [FREE Full text] [doi: 10.1055/s-0038-1668091] [Medline: $\underline{30112741]}$

76. Jones R, Sharkey S, Ford T, Emmens T, Hewis E, Smithson J, et al. Online discussion forums for young people who self-harm: user views. Psychiatrist 2018 Jan 2;35(10):364-368. [doi: 10.1192/pb.bp.110.033449]

77. Kaushik A, Kostaki E, Kyriakopoulos M. The stigma of mental illness in children and adolescents: a systematic review. Psychiatry Res 2016 Sep 30;243:469-494. [doi: 10.1016/j.psychres.2016.04.042] [Medline: 27517643]

78. Stangl AL, Earnshaw VA, Logie CH, van Brakel W, Simbayi LC, Barré I, et al. The health stigma and discrimination framework: a global, crosscutting framework to inform research, intervention development, and policy on health-related stigmas. BMC Med 2019 Feb 15;17(1):31 [FREE Full text] [doi: 10.1186/s12916-019-1271-3] [Medline: $\underline{\text { 30764826] }}$

79. Kelders SM, Kok RN, Ossebaard HC, van Gemert-Pijnen JE. Persuasive system design does matter: a systematic review of adherence to web-based interventions. J Med Internet Res 2012 Nov 14;14(6):e152 [FREE Full text] [doi: 10.2196/jmir.2104] [Medline: 23151820]

80. Lin $\mathrm{H}, \mathrm{Wu} \mathrm{X}$. Intervention strategies for improving patient adherence to follow-up in the era of mobile information technology: a systematic review and meta-analysis. PLoS One 2014;9(8):e104266 [FREE Full text] [doi: 10.1371/journal.pone.0104266] [Medline: 25100267]

81. Epton T, Currie S, Armitage CJ. Unique effects of setting goals on behavior change: systematic review and meta-analysis. J Consult Clin Psychol 2017 Dec;85(12):1182-1198. [doi: 10.1037/ccp0000260] [Medline: 29189034]

82. Melville KM, Casey LM, Kavanagh DJ. Dropout from internet-based treatment for psychological disorders. Br J Clin Psychol 2010 Nov;49(Pt 4):455-471. [doi: 10.1348/014466509X472138] [Medline: 19799804] 
83. de Haan AM, Boon AE, de Jong JT, Hoeve M, Vermeiren RR. A meta-analytic review on treatment dropout in child and adolescent outpatient mental health care. Clin Psychol Rev 2013 Jul;33(5):698-711. [doi: 10.1016/j.cpr.2013.04.005] [Medline: 23742782]

84. Warnick EM, Gonzalez A, Weersing VR, Scahill L, Woolston J. Defining dropout from youth psychotherapy: how definitions shape the prevalence and predictors of attrition. Child Adolesc Ment Health 2011 Jun 15;17(2):76-85. [doi:

10.1111/j.1475-3588.2011.00606.x ]

85. O'Keeffe S, Martin P, Goodyer IM, Wilkinson P, Consortium I, Midgley N. Predicting dropout in adolescents receiving therapy for depression. Psychother Res 2018 Sep;28(5):708-721. [doi: 10.1080/10503307.2017.1393576] [Medline: 29084488]

86. Swift JK, Greenberg RP. Premature discontinuation in adult psychotherapy: a meta-analysis. J Consult Clin Psychol 2012 Aug;80(4):547-559. [doi: 10.1037/a0028226] [Medline: 22506792]

87. Heidi P, Minna A, Lotta K, Kai K, Camilla L, Ville L, et al. The advantages and limitations of digital games in children's health promotion. Finnish J Ehealth Ewelfare 2014;6(4):- [FREE Full text]

88. Olson CK. Children's motivations for video game play in the context of normal development. Rev Gen Psychol 2010 Jun;14(2):180-187. [doi: 10.1037/a0018984]

89. World Health Organization. mhGAP : Mental Health Gap Action Programme: Scaling Up Care for Mental, Neurological and Substance Use Disorders. Geneva, Switzerland: World Health Organization; 2008.

90. Edbrooke-Childs J, Edridge C, Averill P, Delane L, Hollis C, Craven MP, et al. A feasibility trial of power up: smartphone app to support patient activation and shared decision making for mental health in young people. JMIR Mhealth Uhealth 2019 Jun 4;7(6):e11677 [FREE Full text] [doi: 10.2196/11677] [Medline: 31165709]

91. Grist R, Croker A, Denne M, Stallard P. Technology delivered interventions for depression and anxiety in children and adolescents: a systematic review and meta-analysis. Clin Child Fam Psychol Rev 2019 Jun;22(2):147-171 [FREE Full text] [doi: 10.1007/s10567-018-0271-8] [Medline: 30229343]

92. Pihlaja S, Stenberg J, Joutsenniemi K, Mehik H, Ritola V, Joffe G. Therapeutic alliance in guided internet therapy programs for depression and anxiety disorders - a systematic review. Internet Interv 2018 Mar;11:1-10 [FREE Full text] [doi: 10.1016/j.invent.2017.11.005] [Medline: $\underline{30135754]}$

93. George MJ, Odgers CL. Seven fears and the science of how mobile technologies may be influencing adolescents in the digital age. Perspect Psychol Sci 2015 Nov;10(6):832-851 [FREE Full text] [doi: 10.1177/1745691615596788] [Medline: 26581738]

94. Khan KS, Kunz R, Kleijnen J, Antes G. Five steps to conducting a systematic review. J R Soc Med 2003 Mar;96(3):118-121 [FREE Full text] [doi: 10.1258/jrsm.96.3.118] [Medline: 12612111]

\author{
Abbreviations \\ COM-B: capability, opportunity, motivation, and behavior \\ CYP: children and young people \\ CYPMH: children and young people's mental health \\ DHI: digital health intervention \\ MH: mental health \\ MMAT: mixed methods appraisal tool \\ RCT: randomized controlled trial \\ WHO: World Health Organization
}

Edited by G Eysenbach; submitted 11.10.19; peer-reviewed by EB Davies, S Rush, V Ta, C Yeager; comments to author 02.12.19; revised version received 15.01.20; accepted 12.03.20; published 23.06.20

Please cite as:

Liverpool S, Mota CP, Sales CMD, Čǔ̌ A, Carletto S, Hancheva C, Sousa S, Cerón SC, Moreno-Peral P, Pietrabissa G, Moltrecht $B$, Ulberg R, Ferreira N, Edbrooke-Childs J

Engaging Children and Young People in Digital Mental Health Interventions: Systematic Review of Modes of Delivery, Facilitators, and Barriers

J Med Internet Res 2020;22(6):e16317

URL: http://www.jmir.org/2020/6/e16317/

doi: $\underline{10.2196 / 16317}$

PMID: $\underline{32442160}$ 
(CShaun Liverpool, Catarina Pinheiro Mota, Célia M D Sales, Anja Čǔ̌, Sara Carletto, Camellia Hancheva, Sónia Sousa, Sonia Conejo Cerón, Patricia Moreno-Peral, Giada Pietrabissa, Bettina Moltrecht, Randi Ulberg, Nuno Ferreira, Julian Edbrooke-Childs. Originally published in the Journal of Medical Internet Research (http://www.jmir.org), 23.06.2020. This is an open-access article distributed under the terms of the Creative Commons Attribution License (https://creativecommons.org/licenses/by/4.0/), which permits unrestricted use, distribution, and reproduction in any medium, provided the original work, first published in the Journal of Medical Internet Research, is properly cited. The complete bibliographic information, a link to the original publication on http://www.jmir.org/, as well as this copyright and license information must be included. 